6. Ференци В.Н, Елисеев В.Л, Табаков А.А, Огуенко Д.В, Степченков Ю.А., Мухин Д.А., Колосов А.С. Селекция волн в технологии сейсморазведки высокой четкости методом проектирования на области допустимых параметров. Материалы научно-практической конференции «Инновационные технологии и фундаментальная теория в сейсморазведке и сейсмологии», Москва, 2009, с. 11-18.

7. Ференци В.Н., Колосов А.С., Мухин А.А., Мухин Д.А. Вычитание частично нерегулярных волн в методе ОСТ по технологии Сейсморазведки Высокой Четкости // Galperin Readings 2011 - Innovative Technologies and fundamental Researches: 11 Annual International Conference \& Exhibitions, Oct 2011. Moscow, 2011. - Код 107625. - DOI: doi.org/10.3997/2214-4609.20144261.

8. Воскресенский Ю.Н. Построение сейсмических изображений: учеб. пособие для вузов. - М.: РГУ нефти и газа, 2006. - 116 с.

\title{
ВЛИЯНИЕ СОБСТВЕННЫХ (РЕЗОНАНСНЫХ) КОЛЕБАНИЙ ЗДАНИЯ НА РЕЗУЛЬТАТЫ НАТУРНЫХ ИЗМЕРЕНИЙ
}

\author{
А.В. Верхоланцев \\ Горный институт УрО РАН, г. Пермь
}

\begin{abstract}
Аннотация. В работе представлены результаты эксперимента по оценке пространственного распределения резонансных колебаний жилого 14-этажного дома. Работа имеет практический интерес для сейсмологов, ведущих наблюдения в непосредственной близости от зданий и сооружений, а также специалистов, занимающихся вопросами обследования и мониторинга их технического состояния.
\end{abstract}

Ключевые слова: сейсмическое воздействие, резонансы, собственная частота, резонансная частота, микросейсмический шум.

\section{Введение}

Наземные инженерные сооружения, испытывая различные нагрузки (ветровые и/или сейсмические воздействия), находятся в постоянном колебательном процессе. Основными количественными параметрами, характеризующими этот процесс, является собственная (резонансная) частота и логарифмический декремент затухания. Значения этих параметров зависят от многих факторов: это технология и глубина фундамента, размеры в плане, высота сооружения, тип и конструкция перекрытий, материалы несущих конструкций и заполнителя, уровень износа, состояние объекта и многое другое. Для выявления изменений напряженно деформированного состояния конструкций выполняют обследование и мониторинг технического состояния согласно ГОСТ 31937-2011 [2]. При уменьшении в процессе эксплуатации прочностных характеристик несущих конструкций динамические характеристики могут изменяться, и по степени их отклонения от нормы можно судить об изменении прочности сооружения.

Вместе с этим здания сами выступают в качестве источника сейсмических волн. В регистрируемых сейсмических сигналах обычно преобладают колебания первой формы (на основной частоте). Иногда обертоны также являются интенсивными - значения частот определяются конструктивной схемой сооружения [1]. В случае близкого расположения сейсмоприемников к таким источникам наличие в зарегистрированном сигнале помех может затруднять решение некоторых сейсмологических задач. Например, при сейсмическом микрорайонировании референсными методами (метод регистрации микросейсм/землетрясений/взрывов) сейсмическая опасность исследуемой территории может быть оценена не корректно [3]. 


\section{Нормативное регулирование}

Если рассматривать вопрос определения параметров основного тона собственных колебаний в целях обследования и мониторинга технического состояния зданий и сооружений, то нормативным документом в этом вопросе является ГОСТ 31937-2011. Согласно пункту 6.1.2, для повышения уровня полезного сигнала сейсмоприемники размещают на несущих конструкциях верхней части здания, по возможности вблизи оси центра масс здания. Если же рассматривать собственные колебания не как предмет исследования, а как источник помех, тогда можно обратить внимание на РСН 65-87. Согласно пункту 3.3.2 этого документа, который регламентирует технические требования к производству работ по сейсмическому микрорайонированию, в радиусе 150 м от пункта записи не должно быть источников помех.

\section{Цель работы}

На практике при размещении пунктов наблюдения не всегда представляется возможность соблюдать требования к расположению измерительных систем. В связи с этим цель данной работы - изучение пространственного распределения резонансных колебаний инженерного сооружения.

\section{Описание эксперимента и результаты}

Для реализации поставленной цели был осуществлен следующий эксперимент. Объектом исследования выбран 14-этажный кирпичных жилой одноподъездный дом по адресу: г. Пермь, микрорайон Вышка, ул. Гашкова, д.28а. Местоположение выбиралось по следующим критериям:

- здание должно находиться на некотором удалении от других объектов;

- иметь простую геометрическую форму, для явного выделения периода основного тона собственных колебаний;

- должно быть место для реализации профильных наблюдений.

Дом имеет простую форму квадрата со стороной примерно 25 м. Согласно справочному приложению Ж ГОСТ 34081-2017, период собственных колебаний по горизонтальным осям 14-этажного кирпичного здания находится в диапазоне 0.42-0.69 с, что соответствует частотам 1.45-2.38 Гц.

Регистрация фоновых колебаний осуществлялась одновременно пятью сейсмическими станциями, состоящими из портативного модуля сбора данных Reftek 130-01 совместно с трехкомпонентными сейсмоприемниками CMG-6T. Такой комплект позволяет вести непрерывную регистрацию в широком динамическом и частотном (от 0.033 Гц) диапазоне.

Часть станций была размещена непосредственно в здании (на верхнем и среднем этажах, в его основании), остальные - на удалении от здания (50 и 100 м). Схематичное расположение станций представлено на рис. 1. Дальнейшая обработка заключалась в расчете спектров мощности. Для этого брался единый временной интервал (12:00-13:00 местного времени), частотный диапазон для расчета составил 0.1-10 Гц. Полученные спектральные оценки представлены горизонтальной компонентой на рис. 2. Можно отметить, что в рассматриваемом частотном диапазоне выделяется несколько гармоник: 1.60, 2.03, 4.43, 5.13, 5.86, 6.63 и 8.12 Гц. Доминирующая для пунктов N01 (14 этаж) и N02 (7этаж) гармоника 1.60 Гц является собственной (резонансной) частотой здания. Для остальных пунктов максимальная амплитуда связана с частотой 4.43 Гц. 


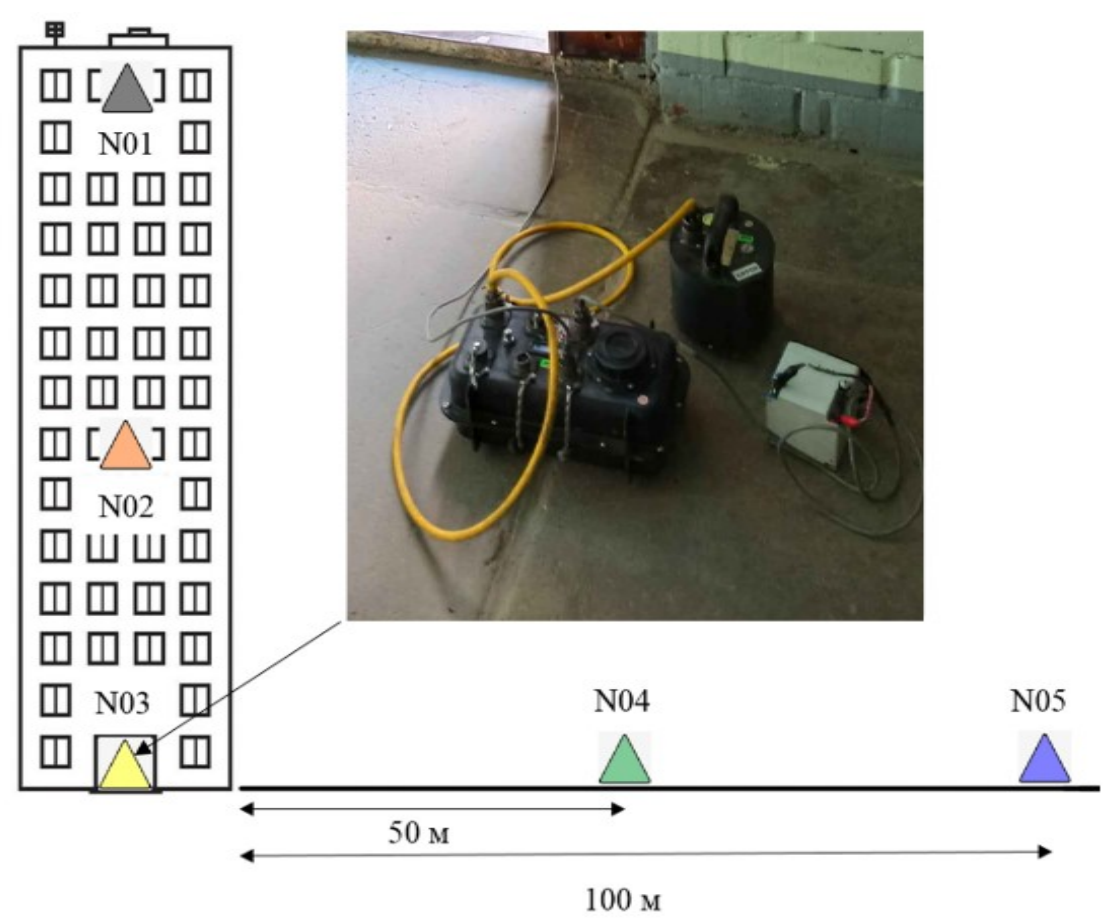

Рис. 1. Схема расположения сейсмических станций

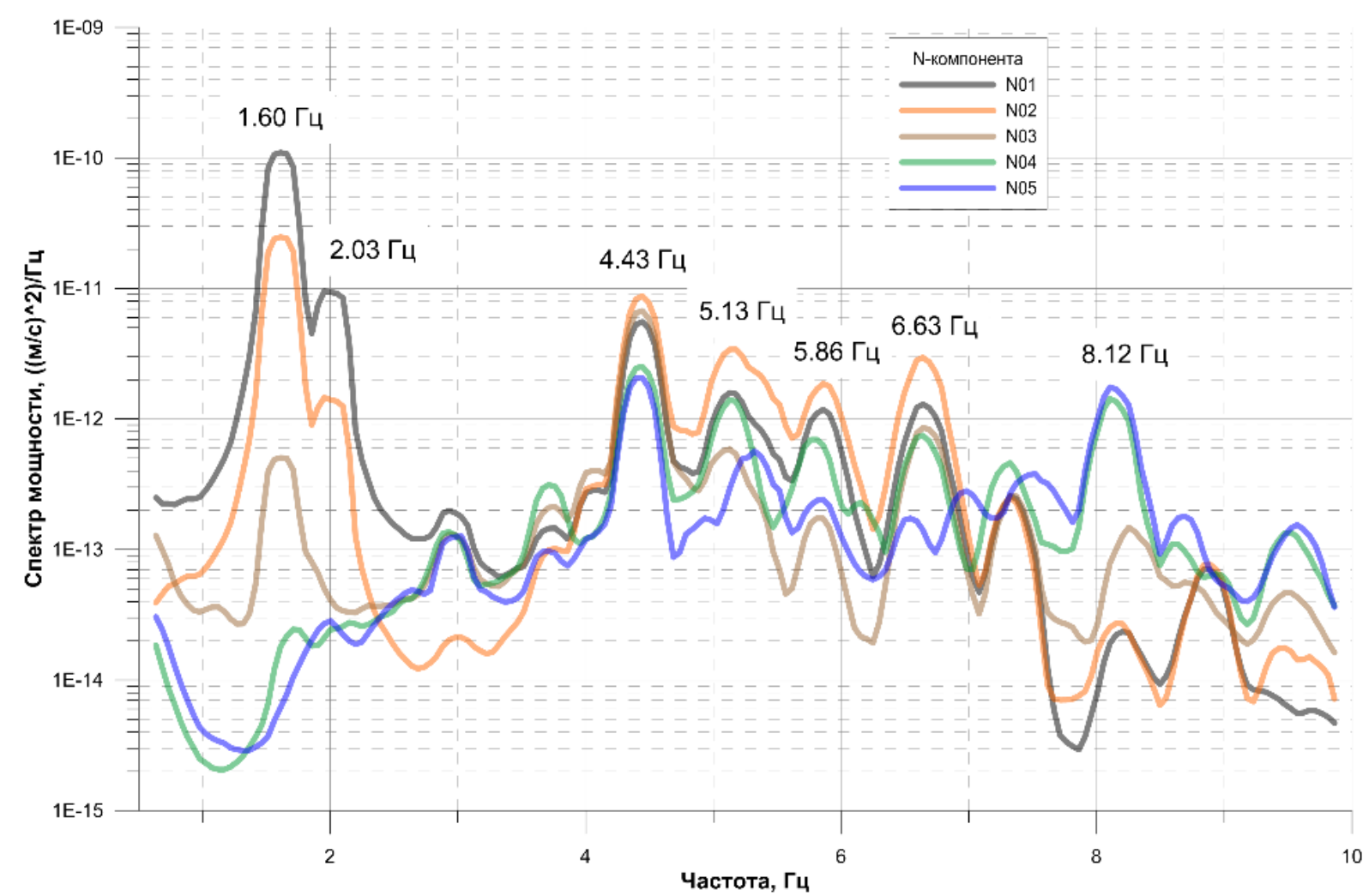

Рис. 2. Спектральные оценки, полученные в здании и за его пределами

Поскольку частота 4.43 Гц присутствует во всех пунктах наблюдения и амплитуда на всех пунктах сопоставима, был сделан вывод, что источник находится в стороне от объекта и связан с работой технологического оборудования. Более сложно ведет себя гармоника с частотой 2.03 Гц. По всей видимости, она является второстепенной гармоникой и прослеживается по записях в пунктах N01 (14 этаж) и N02 (7этаж), но теряется в основании здания. Спектральные оценки, полученные на удалении от здания в пункте 
N04 (50 м) и N05 (100 м) практически полностью совпадают, форма спектра не осложнена гармониками 1.60 и 2.03 Гц. Таким образом, влияния здания как источника сейсмических колебаний на расстоянии 50 м и более не проявляется.

Для сопоставления амплитуд на разных расстояниях по всем выделенным гармоникам определялась спектральная амплитуда для каждого пункта наблюдения. Анализ пространственного распределения колебаний представлен на рис. 3.

Графики изменения спектральной амплитуды позволяют сделать вывод, что исследуемое здание является источником колебаний с частотами 1.60 и 2.03 Гц. Остальные выделенные частоты, по-видимому, не связаны с колебаниями здания. Амплитуды гармоник 4.43, 5.13, 5.86 и 6.63 имеют приблизительно один уровень. По-иному распределились амплитуды для гармоники 8.12 Гц: амплитуда возрастает по мере увеличения расстояния от исследуемого здания, максимум соответствует пункту N05. Это может быть связано с близким расположением источника колебаний на этой частоте к пункту N05 (наиболее вероятно - подземные коммуникации).

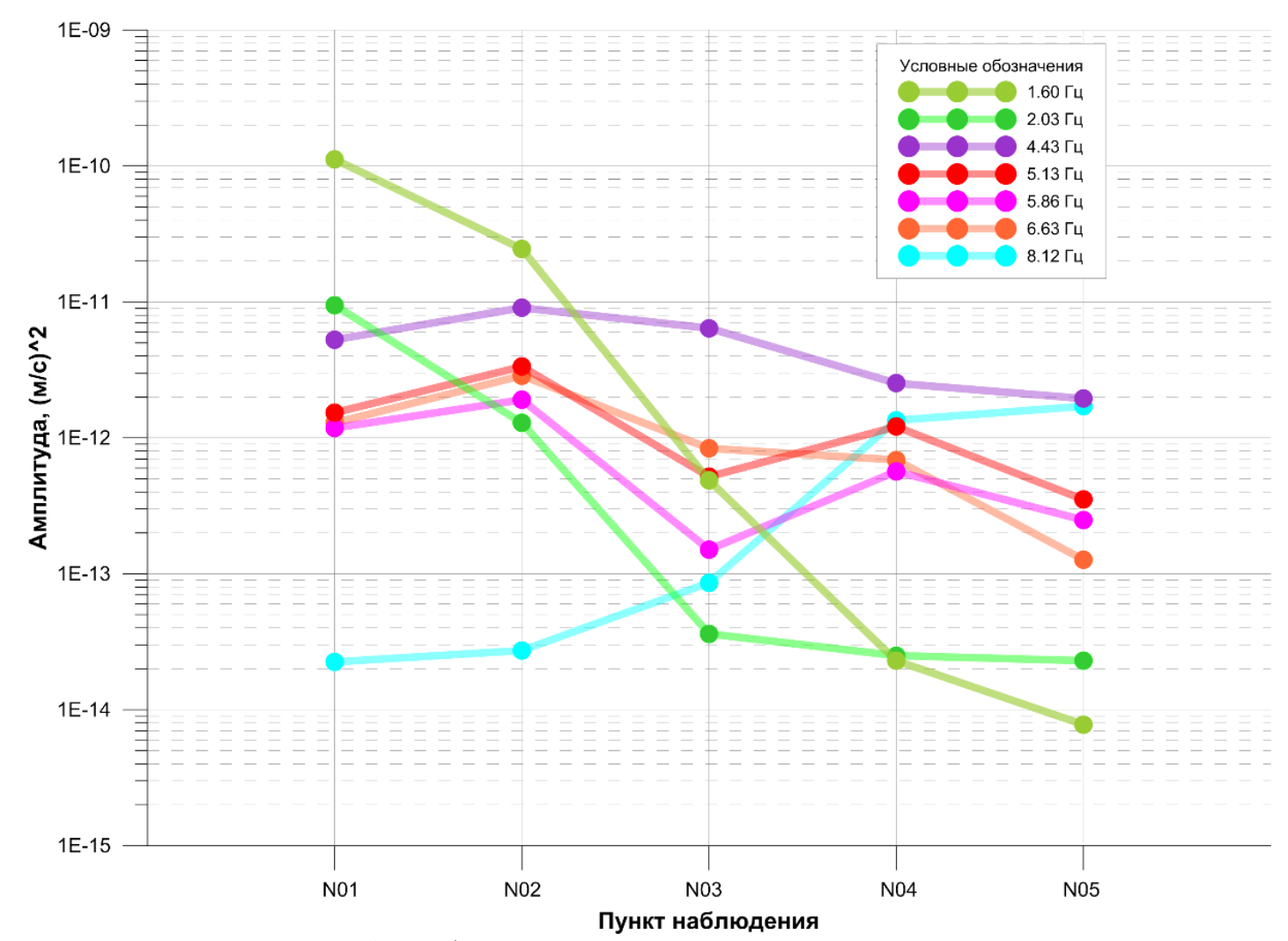

Рис. 3. Графики изменения спектральной амплитуды

\section{Выводы}

Таким образом, для корректного определения периодов собственных колебаний основного тона и обертонов в рамках обследования зданий необходима одновременная регистрация в разных частях исследуемого объекта. Если задача исследования заключается в мониторинге состояния здания, то контроль за динамическими параметрами можно реализовать сейсмической станцией с одним трехкомпонентным сейсмоприемником. Результаты проведенного эксперимента показали, что гармоника, характеризующая собственную (резонансную) частоту, четко прослеживается во всех пунктах внутри здания, в том числе и в его основании.

Выполненный эксперимент показал, что влияния здания как источника сейсмических колебаний практически перестает проявляться на расстоянии 50 м и более. В том случае, 
когда инженерное сооружение все же является источником помех, для минимизации их влияния целесообразно выполнить одновременную регистрацию фоновых колебаний в основании сооружения и в пункте планируемого размещения сейсмической станции. Сравнение спектров позволит выделить колебания, связанные с резонансами здания, и оценить надежность изучаемого частотного диапазона. Такой анализ позволит сформировать набор фильтров, с помощью которых можно будет минимизировать влияние помех.

\title{
БИБЛИОГРАФИЧЕСКИЙ СПИСОК
}

1. Антоновская Г.Н., Шахова Е.В. Способ обследования конструктивной целостности инженерных сооружений // Современные наукоемкие технологии. - 2005. - № 1. - С. 21-22.

2. ГОСТ 31937-2011. Здания и сооружения. Правила обследования и мониторинга технического состояния. - Дата введения 2014-01-01. - М.: Стандартинформ, 2014. - 60 с.

3. РСН 65-87. Инженерные изыскания для строительства. Сейсмическое микрорайонирование. Технические требования к производству работ. - Введ. 1988-01-01. - М., 1998. - 14 с.

\section{ЗАВИСИМОСТЬ ФОРМЫ ГОДОГРАФОВ ПЕРВЫХ ВСТУПЛЕНИЙ ОТ КРИВИЗНЫ ЛИНИИ ПРОФИЛЯ И РЕЛЬЕФА ЗЕМНОЙ ПОВЕРХНОСТИ}

\author{
И.Ю. Герасимова \\ Горный институт УрО РАН, г. Пермь
}

\begin{abstract}
Аннотация: В рамках изучения свойств верхней части разреза возможно определение упругих характеристик по годографам первых вступлений, аппроксимируемых отрезками прямых линий. В реальных условиях за счет влияния различных факторов оси синфазности могут принимать более сложную форму. Рассмотрены погрешности, возникающие при сложной форме профиля наблюдений и рельефе поверхности исследований. Влияние указанных факторов приводит к ошибкам при расчете реальных параметров ВЧР.
\end{abstract}

Ключевые слова: годографы первых вступлений, преломленные волны, верхняя часть разреза.

В основу «классической» обработки годографов первых вступлений в рамках метода преломленных волн заложен этап аппроксимации осей синфазности целевых волн отрезками прямых линий. Это позволяет рассматривать верхнюю часть разреза (ВЧР) в рамках модели однородно-слоистой среды и вычислять ее характеристики в указанном приближении. В реальных условиях годографы первых волн могут принимать сложную форму, и разбиение на группу прямолинейных отрезков становится крайне затруднительным (рис. 1).

Кривизна годографа первых вступлений может быть обусловлена наложением ряда разнородных факторов: интерференцией волн разных классов, дифракцией, кривизной поверхностей преломления, эффектами проницания, переменной линией рельефа и др. [1-3]. Ниже будут рассмотрены только две возможные причины, вызывающие изменение формы годографа: изломанность профильной линии при проведении полевых исследований и сложная форма рельефа поверхности наблюдения.

Искажающий эффект, вносимый разницей между положением пунктов возбуждения и приема вдоль линии профиля (slalom-line) и реальным путем пробега упругих волн, 